\title{
Data Not Releasable
}

National Cancer Institute

\section{Source}

National Cancer Institute. Data Not Releasable. NCI Thesaurus. Code C67110.

Data that can not be released due to confidentiality issues or for other reasons. 